\title{
A beSTA E O SOBERANO: TRÊS NOTAS PARA DERRIDA
}

\section{The Beast and the Sovereign: Three Footnotes to Derrida}

\section{Geoffrey Bennington}

Universidade de Emory

Atlanta, Estados Unidos

\section{Resumo}

Partindo do entrelaçamento original entre os conceitos de soberania e bestialidade elaborado por Jacques Derrida nos seminários de $A$ besta e o soberano, este ensaio investiga as formas pelas quais tal entrelaçamento é pensado por três filósofos que se debruçaram sobre o tema. Em Aristóteles, está em questão a tensão no conceito de homem ideal, aquele que, por ser ideal, não é naturalmente político - politikon zoon - e, portanto, como um deus ou uma besta, fica acima ou abaixo da polis. Sendo superior, é ele quem fará a justiça e as leis, não podendo, consequentemente, fazer parte de um estado. Em Bataille, trata-se de avaliar o modo como o filósofo elabora a associação entre a soberania e a morte, numa lógica de autoperversão ou autoimunidade que fará aflorar a inumanidade do soberano, fazendo com que a soberania seja um constante pôr-se à morte do soberano. Em Heidegger, é possível notar como o filósofo, a partir da leitura de Antígona, propóe e pensa a violência original do conceito de soberania na figura do hupsipolis apolis, isto é, daquele que, por honrar e obedecer as leis do estado, quebrará essas leis e será banido da polis, demonstrando a inseparabilidade entre os conceitos de soberania e bestialidade.

Palavras-chave: Derrida; soberano; besta; Aristóteles; Bataille; Heidegger.

\section{Résumé}

Soulignant la complicité originelle entre les concepts de souveraineté et animalité, dans les séminaires de La bête et le souverain, de Jacques Derrida, cet essai discute les formes dont cette complicité a été pensée par trois philosophes. Chez Aristote, il est question d'une tension dans le concept d'homme idéal, celui qui, pour être idéal, n'est pas naturellement politique - politikon zoon -, et qui, à l'exemple d'un dieu ou d'une bête, reste au-dessus ou en dessous de la polis. Parce que sa supériorité lui permet d'établir la justice et les lois, il n'est pas en mesure de participer d'un état. Chez Bataille, il s'agit de penser la façon dont le philosophe

\section{Abstract}

Based on the original entanglement between the concepts of sovereignty and bestiality developed by Jacques Derrida in the seminars of The Beast and the Sovereign, this paper investigates the ways in which such entanglement is thought by three philosophers who have studied the subject. In Aristotle, the point is the tension in the concept of ideal man, who, being ideal, is not naturally political politikon zoon - and therefore, as a god or beast, is above or below the polis. Being superior, he is the one who will do justice and his own laws, and may not, therefore, be part of a state. In Bataille, it must be evaluated how the philosopher develops 
élabore le rapport entre la souverainetéet la mort, dans une logique d'autoperversion ou d'auto-immunité qui fait éclore de l'inhumain chez le souverain, et qui fait de la souveraineté une mise-à-mort du souverain. Enfin, dans la lecture d'Antigone, chez Heidegger, on remarque une pensée de la violence originelle du concept dans la figure du hupsipolis apolis, c'est-à-dire celui qui, du fait de respecter et d'obéir les lois de l'état, finit par les rompre et par être expulsé de la polis, ce qui souligne la nécessité du lien entre les concepts de souveraineté et d'animalité.

Mots-clés: Derrida; souverain; bête; Aristote; Bataille; Heidegger. the association between sovereignty and death, in a logic of self-perversion or autoimmunity, what will touch on the inhumanity of the sovereign and make sovereignty a constant risk of death to the sovereign. In Heidegger, it is possible to see how the philosopher, from his reading of Antigone, proposes and thinks the original violence of the concept of sovereignty in the figure of hupsipolis apolis, i.e., the one who, in honor and obeying to the laws of the state, will break these laws and be banned from the polis, demonstrating the inseparability of the concepts of sovereignty and bestiality.

Keywords: Derrida; sovereign; beast; Aristotle; Bataille; Heidegger.

“... a pas de loup." (Jacques Derrida)

O soberano, como um Deus, como uma besta, ou como a morte, esses são os resquícios de um "como" que ainda estáo na mesa. Se a soberania fosse (embora eu não o creia) própria ao homem, ela se pareceria muito com esse êxtase expropriador da irresponsabilidade, com esse lugar de não resposta que é comumente e dogmaticamente chamado de bestialidade, divindade ou morte (DERRIDA, 2009: 57).

\section{Aristóteles}

A bestialidade e a divindade (a morte pode ser uma questão para outro dia) ao menos podem ser associadas na tradição de Descartes a Lacan (como Derrida reinvindica no contexto desta citação), mas sua associação começa muito antes, de maneira que se pode sentir tentado a dizer, numa veia derridiana, que os próprios conceitos de soberania, bestialidade e divindade, da forma como os herdamos, dependem dessa associação já de início, desde sua emergência como conceitos, e que jamais houve conceito de divindade, bestialidade ou soberania sem esse tipo de mútua implicação ou contaminação.

Assim, por exemplo, em passagens famosas às quais Derrida se refere na Sessão I de $A$ besta e o soberano I, e depois relê ou ao menos lê em voz alta na sessão final do seminário daquele ano (transcrito da gravaçáo da sua conclusão improvisada para este primeiro ano), Aristóteles já chama a atenção para a associação entre deus e a besta como uma maneira de enfatizar o status "naturalmente" político do homem. Aqui está Derrida citando Aristóteles e interpolando alguns comentários na sessão 13 do ano 1 : 
Fica claro, a partir dessas consideraçóes, que a Cidade é a realidade natural e que o homem é naturalmente um ser destinado a viver em uma Cidade [animal político, tonphusei e polis esti, kai o ti anthropos phusei politikon zoon: é um animal político]; aquele que não tem cidade é, por natureza não por acaso, um ser degradado ou então superior ao homem [aquele que é sem uma Cidade, que é apolis, que é apolítico, está abaixo ou então acima do humano: "aquele que é sem Cidade (kai o apolis dia phusinkai ou dia tukhen, etc.) está, por natureza e não por acaso, abaixo ou entáo acima do homem."]: ele é como o homem que Homero reprova por não ter "clã, lei ou lar"; um homem assim por natureza é, do mesmo modo, belicoso; ele é como um peão isolado no jogo de xadrez (ARISTÓTELES apud DERRIDA, 2009: 347).

Ao que desejaríamos acrescentar uma passagem ligeiramente posterior, à qual Derrida não chega nesta sessão improvisada, na qual Aristóteles diz:

É claro, portanto, que o estado tem prioridade, por natureza, sobre o indivíduo, pois cada indivíduo, quando separado, não é autossuficiente, ele deve estar relacionado ao estado todo como outras partes são ao seu todo, enquanto um homem incapaz de entrar em uma parceria, ou tấo autossuficiente a ponto de não precisar fazê-lo, não é parte de um estado e deve ser, então, um animal

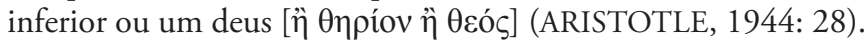

O homem que não é naturalmente político, não é um politikon zoon, fica abaixo ou se ergue acima da polis, que é a realidade natural primária para os humanos, justamente porque, segundo o relato de Aristóteles, a polis é o fim da estória das associações que Aristóteles conta no início da Política, a verdadeira natureza do que está sendo descrito, pois “a natureza de uma coisa é o seu fim" (ARISTOTLE, 1944: 33, ou então, como Aristóteles propóe pouco adiante, é o todo do qual o indivíduo é meramente uma parte e, teleologicamente falando, o todo precede as partes das quais é feito. No caso de "ficar abaixo", essa queda é radical, no sentido de que o homem que não é naturalmente parte da polis não é como qualquer outro tipo de animal: na tradução que acabo de usar, Rackham se esforça um pouco para derivar o "animal inferior" da palavra grega Onpíov, que seria justamente "animal selvagem" (como o oposto do animal doméstico: Jowett simplesmente a traduz como "besta”), mas, de todo modo, um pouco adiante - novamente além de onde Derrida chega nessa sessão final -, Aristóteles é mais explícito:

Pois o homem, quando perfeito, é o melhor dos animais, mas quando separado da lei e da justiça é o pior de todos, uma vez que a injustiça armada é a mais perigosa; ele está equipado com armas desde o nascimento, feitas para serem usadas com inteligência e excelência, as quais ele poderá usar com finalidades piores. É por isso que, se não tiver excelência, ele será o menos sagrado e o mais selvagem dos animais, o mais cheio de luxúria e glutonice (ARISTOTLE, 1944: 31-7).

O homem que cai abaixo de seu lugar natural na polis não escorrega simplesmente para baixo da linha divisória entre o homem e a besta, mas cai ime- 
diatamente, de forma catastrófica e radical, nas profundezas, no fundo mesmo, como o menos sagrado ( $\dot{\alpha} v o \sigma t \omega ́ \tau \alpha \tau o v)$ e o mais selvagem ( $\dot{\alpha} \gamma \rho t \omega ́ \tau \alpha \tau o v)$ dos animais. Na figura aparentemente simétrica daquele que "se ergue acima" (a figura do "melhor" na qual hoje eu quero me concentrar), Aristóteles não relaciona explicitamente o "deus" em questáo à figura do que vem a ser chamado o soberano, mas não precisamos procurar muito na Política (um texto que Derrida, de fato - talvez surpreendentemente - raramente cita) para encontrar ao menos os começos de uma ligação entre esse paralelismo besta-deus, de um lado, e a figura que estaríamos inclinados a chamar de soberano, do outro.

De fato, essa associação interessante e problemática entre divindade e animalidade retorna em uma parte da Política que Derrida usa de forma um pouco diferente em "The Right of the Strongest", o primeiro ensaio de Rogues. Lá, num gesto do qual eu fui anteriormente um pouco crítico (BENNINGTON, 2008), Derrida, ao querer associar a soberania com o que naquele texto ele chama ipseidade, sugere um paralelismo ou convergência entre Platão e Aristóteles, entre O homem de Estado [The Statesman] e a Politica, entre Politikus e Politica, na medida em que ambos supostamente referem seu pensamento político ao motivo do Um, mais obviamente na forma de Deus como o Deus. As transiçóes aqui, nesta primeira seção de "The Reason of the Strongest", são bastante complexas: Derrida acaba de citar Tocqueville (provavelmente via Schmitt, que cita a mesma passagem em Political Theology (SCHMITT, 1985: 49), dizendo que "o povo reina no mundo político da América como Deus reina no universo. Ele [o povo] é a causa e o fim de todas as coisas; tudo nasce dele e é absorvido de volta nele", e segue relacionando essa figura de Deus não diretamente à tradição cristá, mas ao Primeiro Motor de Aristóteles, em si mesmo imóvel. Essa descrição (do Primeiro Motor), do livro Lambda da Metafísica, é então apresentada como um tipo de pretexto para uma volta à discussão explícita da política, pois Aristóteles termina esse livro da Metafísica com uma citação de Homero que sugere uma analogia política explícita para o Deus assim, metafisicamente, descrito. Pularei a citação de Derrida por questâo de tempo, mas o famoso verso de Homero é: "Uma multidão de senhores não é uma coisa boa; que haja somente um senhor, um rei [ouk agathon polykoiranie. heis koiranos esto, heis basileus]". (Este verso de Homero parece ter tido um status quase proverbial e, se tivéssemos tempo, poderíamos seguir seu curso de Aristóteles via Philo Judeaeus, Teofrasto, Eusébio de Cesareia e Dante, a Carl Schmitt, Erik Petersen e Giorgio Agamben ${ }^{1}$ (DERRIDA, 2005: 16). Um pouco depois, no

\footnotetext{
${ }^{1}$ Homero é citado por Brault e Naas na tradução de A. T. Murray; Robert Fagles traduz mais livremente: "Reis demais arruínam um exército - governo do povo! / Que haja somente um comandante, um senhor." Esse verso de Homero, especialmente como citado aqui na Metafisica, de Aristóteles, parece ter adquirido um status quase proverbial, geralmente em contextos explicitamente cristáos. Ele pode ser
} 
mesmo texto, Derrida caracteriza esse gesto como um "salut politique au Dieu Un", "uma saudação política ao Deus Um”, e é isso que, supostamente, pode ser encontrado tanto em Platão quanto em Aristóteles. ${ }^{2}$

Não vasculharei aqui as razóes gerais que me fizeram (e ainda me fazem) pensar que a leitura de Aristóteles aqui está se movendo um pouco rápido demais (mas a questão da velocidade e da desconstrução permanece obscura para mim - pois eu sempre perguntei: "Quão rápida é a boa desconstrução"?). Ao invés disso, gostaria de propor uma abordagem ligeiramente diferente da passagem da Política a que Derrida explicita e precisamente faz referência mas não cita - para apoiar sua associação de Platão e Aristóteles em sua ligação a Deus como o Um. Embora a referência precisa de Derrida aqui permaneça um pouco misteriosa, em parte justamente por ser táo precisa (ARISTOTLE, 1944: 13-15), ${ }^{3}$ a lógica da direção geral nessa parte do Livro III da Política é, de fato, apropriada à questáo. Aristóteles reflete e se pergunta sobre a tensão entre, por um lado, uma visão da justiça e da igualdade e, por outro, a visão de que algum critério de excelência ou eminência (e, desse modo, necessariamente de desigualdade) poderia, no entanto, ser razoavelmente invocado para influenciar a distribuição de cargos políticos. Claramente, qualquer critério de excelência (de desigualdade, portanto, em relação a esse pensamento da justiça como essencialmente relacionada à igualdade) pode ser invocado (ginastas superiores ou flautistas, por exemplo, não são mais qualificados, pela virtude de sua excelência atlética ou musical, para assumir cargos políticos), mas somente

encontrado com usos variados, por exemplo, Philo Judeaeus (On the Confusion of Tongues, Cap. 33); nos Personagens de Teofrasto (N. 29, "A Oligarquia" conhece somente esse verso de toda a obra de Homero e é ignorante do resto); na discussão, em Eusébio de Cesareia, dos "Mártires da Palestina"; no tratado de Dante Da Monarquia, livro I, cap. X, que cita Aristóteles citando Homero; e no famoso capítulo de Bodin sobre a soberania que cita, via Suetônio Calígula citando esse verso, para estabelecer sua própria supremacia. De forma presumivelmente bem independente dos seminários $A$ besta e o soberano, de Derrida (que são, entretanto, explicitamente bastante críticos de Agamben), e de Rogues, esse verso também tem uma função no trabalho atual de Agamben sobre a soberania: em Il Regno et la Gloria (2007), ele, mais de uma vez, cita esse mesmo verso de Homero via o teólogo dinamarquês Erik Peterson, em seu debate com Carl Schmitt. Peterson quer argumentar que o Primeiro Motor de Aristóteles fornece o paradigma para as justificativas subsequentes da monarquia, enquanto a doutrina cristã da Trindade significa que o Cristianismo ortodoxo jamais poderá, de fato, produzir um "teologia política" no sentido de Schmitt. Esse é o ponto crucial da muito tardia resposta do próprio Schmitt a Peterson em Political Theology II, escrito tardiamente em 1969, muito depois da morte de Peterson (Political Theology II: The Myth of the Closure of Any Political Theology, traduzido por Michael Hoelzl (London: Polity Press, 2008)). Ver também a instruída discussão em GERÉBY, György. "Political Theology versus Theological Politics: Erik Peterson and Carls Schmitt”, New German Critique, n. 105, outono 2008: 7-33.

${ }^{2}$ No contexto imediato em que ele cita esse mote de Homero, Derrida discute um pouco o contexto da Ilíada, que invoca a transmissão desta preferida singularidade do governante a partir de Zeus, com referência à sua própria genealogia complexa via Kronos e Ouranos, ligando-a a uma estrutura geral de metafísica patriarcal, falocêntrica e ipsocêntrica. Isso também requer longa análise.

${ }^{3}$ ARISTOTLE, 1994: 13-16, na tradução de Jowett: "Objeçôes podem ser colocadas contra todos os aspirantes ao poder político. Pois aqueles que descobriram que suas reinvindicaçôes de riqueza ou família podem ser interpretadas como não tendo base na justiça; de acordo com esse princípio, se uma pessoa for mais rica que todo o resto, fica claro que deverá ser o governante deles.” 
"a posse de elementos que entram na composição do estado" (ARISTOTLE, 1944: 15). Esses elementos poderiam incluir a liberdade, riqueza e linhagem, mas também a simples superioridade numérica de muitos sobre poucos, assim como a excelência, em um sentido ético mais amplo. Pode parecer que a questão pode ser resolvida facilmente em um dado estado, mas o que dizer - se pergunta Aristóteles na primeira parte da passagem a que Derrida explicitamente se refere nessa referência bastante precisa -, o que dizer do Estado no qual todos esses elementos diversos coexistem? Em um Estado no qual há pessoas ricas $e$ boas $e$ bem nascidas (e essas pessoas não são as mesmas), como poderemos decidir quem começará no poder? "Objeçôes", diz ele na segunda parte da passagem que Derrida aponta em sua referência, "podem ser levantadas contra todos os aspirantes ao poder político". Essas objeçôes "aparecem para mostrar que nenhum dos princípios a partir dos quais os homens reivindicam o poder e justificam manter todos os outros homens em submissão [é] correto."

A implicação de Derrida é que, face a essa dificuldade que surge da coexistência de "diversos elementos" em um Estado (e o Estado não seria, de fato, um Estado na construção de Aristóteles, se não houvesse uma multiplicidade e diversidade de elementos, sendo esse o princípio mesmo de suas críticas constantes à República de Platão e, notadamente, da reivindicação de Sócrates de que o melhor estado é aquele que mais se assemelha a um indivíduo (República, 462c), Aristóteles, contudo, propóe a superioridade d'O Um na imagem da ipseidade suprema de Deus que, na Metafísica, reivindicou a citação de Homero sobre a preferência por um governante. De fato, Aristóteles passa imediatamente a considerar o caso do Rei Absoluto ou pambasileus, o caso d"O Homem Ideal", como Newman também glosa em seu comentário clássico sobre a Política (NEWMAN, 1887: 273-281). Complicando, porém, a reivindicação de Derrida sobre a redução da diversidade na figura do Um, é plausível ler essa discussão não simplesmente como recomendação dessa solução aos problemas surgidos da multiplicidade, diversidade e diferença, mas como se já empurrasse a um certo limite a lógica paradoxal - autoimune - da soberania que Derrida se preocupa em desenvolver, ele mesmo, tanto em $A$ besta e o soberano quanto em Rogues.

É assim que Aristóteles introduz o Homem Ideal:

Se, entretanto, houver um ou mais indivíduos, embora não o suficiente para criar o complemento total de um estado, cuja excelência seja táo proeminente [literalmente: tão hiperbólica] que a excelência ou capacidade política de todo o resto não admita qualquer comparaçáo com a dele ou deles, ele ou eles não pode (m) mais ser visto(s) como parte de um estado; pois a justiça não será feita ao superior, se se considerar que ele seja somente igual àqueles que são, até o momento, inferiores a ele em excelência e capacidade política (ARISTOTLE, 1944: 3-10).

Esse "não pode $(\mathrm{m})$ mais ser visto(s) como parte de um estado" naturalmente nos faz lembrar a caracterização inicial do homem apolítico con- 
tranatural e, assim, não chega a ser surpresa ver Aristóteles imediatamente caracterizar tal proeminência como sendo a de um Deus e de uma certa excepcionalidade com relação à lei; tampouco causa surpresa que essa situação, que Derrida consistentemente demonstra nos seminários de $A$ besta e o soberano, evoca uma fábula animal:

Tal homem pode verdadeiramente ser considerado como um Deus entre os homens. Por isso, vemos que a legislação necessariamente concerne àqueles que são iguais no nascimento e na capacidade, e para homens de proeminente excelência não há lei - eles mesmos são a lei. Qualquer um que tentasse fazer as leis por eles seria ridículo, eles provavelmente iriam retorquir com o que, na fábula de Antístenes, os leóes disseram às lebres, quando no conselho das bestas as últimas começaram a resmungar e reclamar igualdade para todos (ARISTOTLE, 1944: 10-17; a tradução de Rackham traz uma nota útil sugerindo o que os leóes teriam dito às lebres: "Onde estão suas garras e dentes?”). ${ }^{4}$

Tal indivíduo (ou grupo, mas a lógica da proeminência não falha em produzir a imagem do indivíduo, da qual surgem os muitos problemas nas teorias da soberania) proeminente ou hiperbolicamente excelente é menos uma solução de Aristóteles para sua questão do que um problema a mais para ela, isto é, um tipo de caso-limite do político como tal - de onde um grau de simpatia na discussão de como até mesmo as formas "imperfeitas" ou anormais de Estado lidam com tais casos, por meio do exílio ou ostracismo de tais indivíduos proeminentes, nos quais Aristóteles reconhece que "há um tipo de justiça política".

De fato, esse "problema" (Aristóteles usa, de fato, o termo problema) precede a distinção entre as formas normais e anormais de estado e, portanto, mobiliza as próprias definições básicas do estado e, desse modo, também a do zoon politikone do zoon logon ekhon, que constituem a estrutura da Politica

\footnotetext{
${ }^{4}$ Sobre a nota de Rackham: provavelmente inspirado em Newman, Vol. III, $c f$. a parábola do desarmamento de Churchill em um discurso de 24 de Outubro de 1928: "Era uma vez, todos os animais do zoológico decidiram que eles iriam se desarmar e eles organizaram um conferência para organizar o assunto. O Rinoceronte, então, disse, ao abrir os procedimentos, que o uso dos dentes era bárbaro e horrível e deveria ser estritamente proibido por consenso geral. Os chifres, que eram armas principalmente defensivas, tinham que ser permitidos. O Búfalo, o Veado, o Porco-Espinho e até mesmo o pequeno Ouriço, todos disseram que votariam com o Rinoceronte, mas o Leão e o Tigre tinham uma visão diferente. Eles defendiam os dentes e até mesmo as garras, que descreveram como armas honoráveis de antiguidade imemorial. A Pantera, o Leopardo, o Puma e a tribo toda dos pequenos felinos apoiaram o Leão e o Tigre.

O Urso então falou. Ele propôs que tanto dentes quanto chifres deveriam ser banidos e nunca mais usados para a luta por animal algum. Seria suficiente se aos animais fosse permitido se dar um bom abraço toda vez que brigassem. Ninguém poderia objetar a isso. Era tấo fraterno, e seria um grande passo em direção à paz. Todos os outros animais, entretanto, ficaram muito ofendidos com o urso e o Pavão entrou em perfeito pânico.

A discussão esquentou tanto e ficou tão agressiva, com todos aqueles animais começando a pensar muito sobre chifres, dentes e abraços quando discutiam sobre as intençóes pacíficas que os reunira, que eles começaram a se olhar com repugnância. Felizmente os responsáveis conseguiram acalmá-los e persuadi-los a voltarem em silêncio às suas jaulas, ao que eles voltaram a se sentir novamente amistosos uns com os outros."
} 
como um todo. "O problema é universal, concerne igualmente a todas as formas de governo, verdadeiros ou falsos" (ARISTOTLE, 1944: 4-5), diz Aristóteles; nas formas imperfeitas ou anormais de estado (aquelas nas quais o estado não é governado com vista ao bem comum) o uso do exílio ou ostracismo pode ser justificado ou ao menos compreensível, mas em uma forma correta de estado o uso do exílio ou ostracismo daria ensejo a graves dúvidas quando usados não somente contra alguém proeminentemente abastado, forte ou popular, mas precisamente quando essa proeminência advém da excelência ética ou política, i. e., prominência na justiça mesma, que Aristóteles afirmara, "implica todas as outras [excelências: i.e., riqueza, força, nascimento e assim por diante]": em outras palavras, a tensão interna que acabamos de notar na caracterização da justiça igualdade emerge nesta altamente problemática figura da eminente desigualdade que Newman chama de $\mathrm{O}$ Homem Ideal. Somente aqui, nesse caso excepcional e não em geral, a "solução"de Aristóteles envolve - como quando se procura ver o lado bom de algo ruim - um tipo de derradeira tentativa de incluir $\mathrm{O}$ Homem Ideal naquele Estado do qual, como vimos, ele não pode ser parte:

As pessoas não dirão que tal homem deve ser expelido e exilado; por outro lado, ele não pode ser um sujeito - isso seria como se a humanidade pretendesse reinar sobre Zeus, dividindo seus cargos políticos com ele. A única alternativa é que todos devam alegremente obedecer a tal governante de acordo com o que parece ser a ordem da natureza, entáo homens como ele deveriam ser reis nos seus estados para a vida toda (ARISTOTLE, 1944: 29-34).

A hipótese de $\mathrm{O}$ Homem Ideal ou pambasileus, então, a hipótese do soberano, seríamos tentados a dizer, representa um caso limite para a política como tal e para a definição mesma da polis. Não somente é esse caso excepcional pelo fato de que, como Aristóteles parece reconhecer, é difícil que ele aconteça, mas também pelo fato de que tal homem divino ou bestial estaria fora da lei, porquanto ele é a lei. Isso dá lugar a uma aparente complicação na distribuição dos termos aqui, pois, diz Aristóteles resumindo um argumento antimonárquico e incluindo uma famosa definição:

Aquele que proclama o governo da lei pode acabar proclamando somente o governo de Deus ou da Razáo; mas aquele que proclama o governo do homem acrescenta um elemento da besta [thurion novamente], pois o desejo é uma besta selvagem e a paixão perverte os coraçóes dos governantes, mesmo quando são os melhores homens. A lei é a razão não afetada pelo desejo (ARISTOTLE, 1944: 28-31).

Essa relação entre o soberano e a lei é o ponto crucial do conceito de soberania em toda a tradição. Como fica explicitamente claro a partir ao menos de Bodin, é uma parte essencial da definição de soberano (talvez a parte essencial) que ele possa estar apto a fazer a lei e, consequentemente, quebrá-la - e como 
o soberano não está circunscrito pela lei (até mesmo ou especialmente a lei que ele faz), essa quebra da lei tem prioridade conceitual. Como Derrida mostra claramente ao longo dos seminários, o potencial para trocas analógicas entre a besta e o soberano e entre o soberano e o criminoso depende justamente dessa posição fora da lei e toda essa configuração, naquilo que Derrida às vezes chama de "estranheza” (“uncanniness") (DERRIDA, 2009: 249-50), parece ter sido já programada por Aristóteles. Justamente por causa das propriedades paradoxais da soberania nessa descrição, parece plausível dizer que noçóes aparentemente divergentes de soberania ainda estão explorando possibilidades que já estão em ação na tradição aqui aparentemente inaugurada por Aristóteles.

\section{Bataille}

Bataille praticamente não aparece na reflexão posterior de Derrida sobre a soberania e é, no máximo, objeto de alguns comentários alusivos. Em $A$ besta e o soberano I, durante a discussão de Celan, Derrida desenvolve uma lógica da "surenchère" [aumentando a aposta] que leva o pensamento da soberania para além da soberania, no caso de Celan, uma soberania poética além da soberania política, e associa esse pensamento de uma dinâmica da soberania a Valéry, Nietzsche e Bataille:

Há a majestade soberana do soberano, o Rei, e há, mais majestoso ou diferentemente majestoso, mais soberano ou diferentemente soberano, a majestade da poesia ou a majestade do absurdo, na medida em que ela dá testemunho da presença dos humanos. Esse aumento hiperbólico da aposta é inscrito no que chamarei de dinâmica da majestade ou da soberania, em sua dinâmica, pois estamos lidando com um movimento no qual a precipitação é inelutável, e a dinâmica (escolho essa palavra deliberadamente) porque estamos lidando com o soberano, especificamente com poder, com potência (dynamis), com a realocaçáo da potencialidade do dinasta e da dinastia. O que equivale a dizer que "há algo mais majestoso" que a majestade do rei, assim como Monsieur Teste, vocês se lembram, foi descrito como superior ao homem superior, ou o além-homem de Nietzsche como acima do homem superior. Como em Bataille, a soberania, no sentido que ele concebe e dá a ela, excede a soberania clássica, especialmente a do mestre, do lorde, do poder absoluto etc. (Voltaremos a esse ponto adiante. Insista nesse "mais" e o vazio).

Mas então, porque manter a palavra? (DERRIDA, 2011:307). ${ }^{5}$

A soberania talvez exceda a soberania clássica, mas o faz por meio da, ou talvez devêssemos dizer a partir da lógica da soberania clássica mesma, que parece oferecer uma razáo promissora para manter a palavra. O que Derrida

\footnotetext{
${ }^{5}$ Interessantemente, uma nota do Editor neste ponto do texto, em $A$ besta e o soberano I, mostra que a bibliografia de Derrida para a versão norte-americana desse seminário inclui referências a Bataille e a seu próprio texto anterior, "From Restricted to General Economy", em A escritura e a diferença.
} 
chama, em Rogues, de "contraconceito de soberania à la Bataille"6 talvez seja especialmente perverso por simplesmente desenvolver, por assim dizer, os recursos do conceito clássico, uma das peculiaridades da qual é ele autoperversor em sua lógica hiperbólica ou, como o último Derrida preferiria dizer, autoimune. Quanto mais soberano o soberano se torna, quanto mais ele se torna ele mesmo, i.e. soberano, menos soberano ele também se torna. Esse movimento irrepresentável (como uma nota marginal a esse momento em $A$ besta e o soberano I coloca, o "quanto mais, mais..." da soberania que leva a alguma coisa outra que a soberania, ou à soberania mesma como algo sempre mais e outro do que ela mesma) é, poderíamos pensar, exatamente o que está em jogo no esforço de Bataille em pensar a soberania e fazê-lo, além do mais, com uma atenção constante à besta. A perversão ou perversidade aqui é uma rigorosa consequência da lógica que acabamos de ver em ação na Política de Aristóteles.

A noção de soberania em Bataille é notável não somente por reconhecer esse aspecto hiperbólico de autoperversão do conceito de soberania mesmo (tal reconhecimento permite a ele, como descrito no ensaio anterior de Derrida sobre ele, des- e re-inscrever conceitos hegelianos de um modo não-hegeliano ${ }^{7}$ ), mas por reconhecer um outro paradoxo por meio do qual a hipérbole produz sua própria falência ou colapso. $\mathrm{O}$ conceito de soberania prescreve o "quanto mais, mais", como a nota marginal de Derrida descreve, de tal maneira que Bataille, pelo menos nessa ocasiáo, aparece como um cume, um ápice no qual o mais alto seria, de fato, o mais alto, no qual a soberania seria alcançada. Porém, Bataille também reconhece que, na medida em que eu falo (e devo falar, se quero evitar a mera animalidade na conceitualidade de Bataille), eu sou então necessariamente menos soberano, preso na inevitável temporalidade servil da linguagem. Ao proclamar a minha soberania, sou menos que soberano. Como Bataille propõe na notável seção "Ápice e declínio" de seu estranho livro Sur Nietzsche $e^{8}$

\footnotetext{
6 "[...] se a voyou-cracy representa um tipo de poder rival, um desafio ao poder do estado, uma contrassoberania criminal e transgressiva, temos aqui todos os elementos de uma contrassoberania à la Bataille. Além do domínio, além do conceito e do estado hegeliano, além ou contrariamente à noção clássica de soberania, a soberania de que fala Bataille cultiva o mal e o sexual, assim como a transgressão poética." (DERRIDA, 2003: 100; DERRIDA, 2005: 68-9; traduçấo ligeiramente modificada).

7 "Tomados um a um e imobilizados fora de sua sintaxe, todos os conceitos de Bataille são hegelianos. Devemos reconhecê-lo e não parar aí. Pois se não se apreende o rigoroso efeito de tremor a que ele submete esses conceitos, a nova configuração na qual ele os desloca e reinscreve, mal tocando neles, concluir-se-ia, dependendo do caso em questão, que Bataille é hegeliano, anti-hegeliano ou que ele embaralhou Hegel. Estar-se-ia errado cada vez" (DERRIDA, 1967: 373; 1978: 253). Desnecessário dizer que tudo o que adiantamos aqui aceita os princípios da leitura textual que Derrida estabelece nesse ensaio.

${ }^{8}$ A tradução para o inglês de Bruce Boone (London: Continuum, 1992), de leitura fácil, por um lado, é, porém, muito descompromissada com propósitos acadêmicos: todas as traduçôes do francês bastante idiossincrático de Bataille sấo minhas.
} 
(BATAILLE, George, 1973: 5-205), recorrendo à topologia acima/abaixo do homem naturalmente apolítico de Aristóteles:

Este estado de disponibilidade feliz [disponibilité: abertura] não é humanamente concebível. A natureza humana não pode, como tal, rejeitar a preocupação com o futuro: os estados nos quais tal preocupação não nos tocam mais estão acima ou abaixo da humanidade (BATAILLE, 1973: 54).

A impossibilidade do ápice da soberania de fato acontece com a linguagem: "Eu vivo e a vida (linguagem) está em mim" (BATAILLE, 1973: 61), o que significa que falar do ou no ápice implica em uma medida de servilidade e, portanto, alguma outra coisa que não o ápice: "O fato de 'falar' de uma moralidade do ápice mesmo vem sob uma moralidade em declínio. [...] A construçẫo e exposição de uma moralidade do ápice pressupõe um declínio de minha parte, uma aceitação das regras morais que depende do medo. Na verdade, o ápice proposto como objetivo não é mais o ápice: eu o reduzo à disputa por lucro porque eu falo dele. [...] Assim como o ápice é, ao final, somente o inacessível, o declínio já de saída é inevitável" (BATAILLE, 1973: 56-7). Portanto, "o ápice não pode ser afirmado, ninguém pode falar em seu nome” (BATAILLE, 1973: 104), e isso leva a uma lógica quase suicida da soberania mesma:

A soberania do desejo, da ansiedade, é a ideia mais difícil de se entender. Pois o desejo se esconde. $\mathrm{E}$ a ansiedade se mantém silenciosa (nada afirma). Do outro lado da soberania vulgar, a ansiedade e o desejo parecem perigos. Do lado da ansiedade, do desejo, de que serve a soberania?

E o que significa a soberania se ela não reina, se não é reconhecida por ninguém, se deve ser assim e até mesmo se esconder, com nada a seu respeito que não seja ridículo e não confiável?

Ainda assim eu imagino a autonomia de momentos de angústia ou alegria (de êxtase ou prazer físico) como os menos questionáveis. O prazer sexual (que se esconde e se presta ao escárnio) toca no aspecto essencial da majestade. Assim como o desespero. Porém, aqueles em desespero e aqueles em prazer não conhecem sua majestade. E se eles a conhecessem, eles a perderiam. A autonomia humana necessariamente se esvai (ela se aprisiona ao se afirmar). A verdadeira soberania é o colocar-se à mercê da morte conscientemente de tal maneira que não mais se pode perguntar sobre esse colocar-se à mercê da morte (BATAILLE, 1973: 118-119).

$\mathrm{O}$ insight de Bataille acerca de uma inumanidade intrínseca da soberania, por um lado, e uma relação intrínseca com o pôr à morte, por outro, não somente se relaciona ao que o volume sobre a Soberania postumamente publicado chama de "o reino milagroso do 'não-conhecimento"' (BATAILLE, 1976: 252), mas também ajuda a explicar a persistente conexão entre a soberania e a morte violenta. Não se trata de simplesmente o soberano ter o poder sobre a vida e a morte (como reverenciado na tradicional "marca" da soberania como o poder de impor e/ou suspender a pena de morte, como frequen- 
temente nota Derrida), mas de o soberano ser inexoravelmente atraído, justamente pela lógica do ápice, em direção ao pôr à morte.

Essa relação entre a morte e a soberania é, obviamente, um problema tradicional na teologia política, ao menos desde Bodin, e é um problema sério o suficiente para fazer surgir a doutrina dos "dois corpos do Rei" como um meio de justificar a continuidade da soberania que, caso contrário, seria posta em dúvida sempre que o monarca morresse. (Esse é um dos raros pontos em que a filosofia política clássica é rancorosamente forçada a reconhecer uma vantagem na democracia, na qual a morte natural não coloca a continuidade do soberano em risco.) $)^{9} \mathrm{O}$ insight de Bataille, porém, é mais preocupante porque implica que é parte da lógica da soberania, não somente que o soberano seja exposto ao risco da morte natural, mas que a soberania seja mais essencialmente ligada ao pôr à morte não natural. Nos termos paradoxais de Bataille, a soberania implica em sacrifício, mas o objeto proeminente do sacrifício é o soberano mesmo.

Isso fica claro não somente no volume intitulado Soberania, mas também na obra inacabada Teoria da religião e nos materiais a ela associados. Por exemplo, em um dos dois discursos proferidos em 1948 sob o título "Esquema para uma história das religióes", Bataille desenvolve o pensamento aparentemente dialético de que o homem emerge da animalidade (definida como o domínio da imanência, no qual os animais são, na memorável frase repetida como uma litania em Teoria da religiāo, "como água na água") (BATAILLE, 1976b: 292; 295-6) ao se separar do mundo-objeto, que ele domina. Essa dominação, porém, o leva a outra dominação, que é conseguida pela destruição do objeto e por um impulso para mais uma vez adquirir imanência: essa destruição acontece mais notadamente na morte ritual dos animais, na qual o homem, tendo primeiramente emergido da animalidade, de certa forma a ela novamente se junta na forma de uma violência festiva. (No volume Soberania, Bataille se refere ao "retorno à animalidade que percebemos na soberania" somente para destacar que a animalidade a que se "retorna" não é a mesma animalidade que a animalidade da qual o homem partiu (BATAILLE, 1976a: 612). Essa não-identidade é o princípio dos superlativos (o mais profano, o mais selvagem) que vimos da descrição que Aristóteles faz do homem apolítico). Uma forma mais desenvolvida dessa dialética ocorre no nível da comunidade engajada na violência beligerante contra outras comunidades e capturando escravos que são subsequentemente mortos: nesse pôr à morte a violência externa da guerra é internalizada e se reúne à manifestação interna da violência festiva: essa reinternalização significa que:

\footnotetext{
${ }^{9}$ Ver, por exemplo, a discussão de Hobbes em Leviatã, capítulo XIX. Disponível em: <http:// oregonstate.edu/instruct/phl302/texts/hobbes/leviathan-contents.html>
} 
É somente na medida em que o homem da tribo, ele mesmo, acaba sendo sacrificado que essa liberaçáo interna da violência assume todo o seu significado.

De tal forma que, logicamente, na base da liberação dessa violência interna contra o escravo, essa violência interna é necessariamente liberada contra o próprio membro da tribo e não exatamente contra qualquer homem da tribo, mas contra aquele que corporifica a tribo ao máximo, notadamente contra o soberano, contra o rei.

É esse pôr à morte do rei que é o produto dessa liberação da violência interna (BATAILLE, 1976a: 413; ver também BATAILLE, 1976: 318).

Esse momento paradoxal da soberania como um sentido de fim da soberania é afirmado muitas vezes em Bataille. Em Soberania, por exemplo: "O pôr à morte do soberano é a maior afirmação da soberania: o rei não pode morrer, a morte é nada para ele, é aquilo que sua presença nega, o que sua morte mesma reduz a nada” (BATAILLE, 1976: 270; ver também BATAILLE, 1976: 249). Matar o rei, então, não é só a eventualidade externa que viria de fora para ameaçar a soberania, mas é parte da lógica (ou da dinâmica) da soberania mesma, que contém um momento autodestrutivo ou suicida. $\mathrm{O}$ regicídio, que Derrida, em um texto sobre psicanálise, renomeia como "paregicídio", é, de fato, "paregisuicídio". ${ }^{10}$ Nessa leitura "perversa" que Bataille faz da soberania, então, o tipo de horror racional que atinge Kant na forma de uma nota de pé de página da Metafísica da moral que discute a execução de Carlos I e Luís XVI, o "abismo que irrecuperavelmente engole tudo" (KANT, 1996: 97) (Derrida discute essa passagem com mais detalhe na oitava sessão do segundo ano dos seminários sobre a Pena de Morte, ainda inédita), é mais assustador pelo fato de que ele é gerado pela própria lógica da soberania: uma vez que a soberania é marcada pelo princípio interno da falha perversa que Bataille identifica, ela está a caminho, então, da destruição, do sacrifício, do suicídio ou simplesmente da execução."

\section{Heidegger}

As estruturas desnorteadoras e incomuns da soberania em sua afinidade com o homem (contra) naturalmente apolítico como estando acima e/ou fora da polis, como deus ou besta ou ambos, não deixam de nos lembrar

\footnotetext{
${ }^{10}$ Derrida cunha o termo "paregicídio" em: Etats d'âme de le psychanalyse. Paris: Galilée, 2000: 50-51; traduzido por Peggy Kamuf como "Psychoanalysis Searches the States of its Soul". In: DERRIDA, Jacques. Without Alibi. Stanford: Stanford University Press, 2002: 259-60. Eu sugeri a extensão ao "paregisuicídio" em um texto de 2001 escrito em francês e intitulado "Superanus" (na conferência sobre "A Soberania" nas Journées Philosophie-Psychanalyse de Castries, Château de Castries), publicado em inglês em Theory and Event, v. 8, n. 1, 2005, revista eletrônica não paginada.

${ }^{11}$ Em um texto inédito intitulado simplesmente "Execution", eu mostro como, exemplarmente no pensamento político de Rousseau, a inabilidade da soberania em ser soberana imediatamente mostra sua necessidade de um braço ou ramo executivo, que inevitavelmente, entáo, usurpa o poder soberano e, pode-se dizer, procede à execução da soberania.
} 
os engajamentos repetidos de Heidegger com um verso surpreendente da Antígona, de Sófocles, que usa a expressão apositiva hupsipolis apolis.

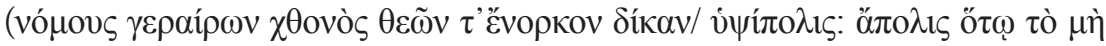

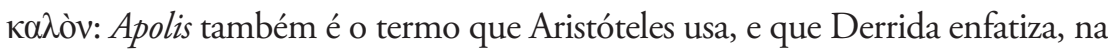
abertura da Politica.) Heidegger primeiramente comenta sobre isso na Introdução à metafisica, em 1935, e volta a esse assunto com mais detalhe, e com algumas notas de passagem sobre o nacional-socialismo, no curso de 1942 sobre o poema de Hölderlin Der Ister (o curso que é o pretexto para o filme homônimo: mas se a memória serve, a hupsopolis apolis não fez dele filme). Há algumas diferenças interessantes entre esses dois tratamentos, mas não terei tempo de comentá-las aqui, tampouco em alguns tópicos curiosamente relacionados na scholarship heideggeriana (Bestegui, Fried, Žižek). O contexto desse verso na Ode Coral, por vezes conhecida como "Ode ao Homem", na qual o Coro começa proclamando que o homem é deinon e até mesmo deinotaton, o mais maravilhoso, o mais formidável, o mais terrível, o mais estranho ou, como Heidegger prefere traduzir, o mais unheimlich, o mais estranho. O Homem, continua o Coro, domina o mundo natural, navega os oceanos até mesmo contra o vento, semeia a terra, captura e domestica as bestas, aprendeu sozinho a fala e o pensamento com os quais organiza a polis e, resumidamente, tem até recursos a favor e contra toda eventualidade, exceto a morte. A sutileza desses recursos, esses tekhnai, permite ao homem se mover "ora para o mal, ora para o bem": e ora, na tradução de Jebb: "Quando ele honra as leis da terra e a justiça dos deuses à qual deve obedecer por juramento, sua cidade prospera [hupsipolis]; mas banido de sua cidade [apolis] será aquele que, graças à sua precipitação, a ela traz desgraça." (A palavra hupsipolisé, acredito, um hapax logomenon: dicionários diferentes a relacionam de forma variada a polis ou ao cidadáo e sugerem que seja traduzida como "elevado ou honrado em sua cidade" ou, então, como "cidadão de uma cidade orgulhosa".) Tradutores e editores de Sófocles geralmente colocam pontuação entre as duas palavras, mais tipicamente dois pontos ou ponto e vírgula para realçar a justaposição das duas possibilidades - se o homem obedece as leis, entáo hupsipolis; se não, entáo apolis. Os scholars sofoclianos certamente reconhecem uma tensáo extrema nessa formulação e a dificuldade de analisar como atribuir a dois adjetivos (a questão crítica padrão é: o que em Creonte ou Antígona deve ser considerado hupsipolis e o que deve ser considerado apolis??). George Steiner, que vê aqui uma "concisão gnômica disponível somente à poesia suprema”, também propõe (sem dignar-se a fornecer qualquer evidência), que "poucas palavras fora da escritura têm atraído mais intenso comentário ou tido um legado mais diverso de realização teórica e existencial” (STEINER, George, 1996: 254). ${ }^{12}$ Heidegger ignora tal implicação na

\footnotetext{
${ }^{12}$ Como sempre, em tais proposiçóes, Steiner também aspira a ser gnômico, mas ele alcança algo mais parecido com um jardim gnômico.
} 
pontuação e distribuição e toma as duas palavras rigorosamente juntas, mais como sinônimos do que como antônimos, e assim comenta na Introdução à metafísica:

[poetas, pensadores, padres e governantes] usam a violência como agentes da violência [als gewalttätige Gewalt brauchen] e se tornam aqueles que mais se destacam no Ser histórico como criadores, como agentes. Ao se destacar na história [hupsipolis, portanto], eles também se tornam apolis, sem cidade ou lugar, solitários, estranhos, sem saída entre seres como um todo e, ao mesmo tempo, sem regulamentação ou limite, sem estrutura ou adequação <Fug , porque como criadores eles devem fundamentar tudo isso em cada caso (HEIDEGGER, 2000: 162-3). ${ }^{13}$

Parece que a figura da hupsipolis apolis, com a violência inaugural associada como sua condição (anterior à distinção que as leituras mais tradicionais de Sófocles fariam entre a hupsipolis seguidora da lei e a apolis que quebra a lei) e que Heidegger quer associar a um correr risco criativo pelo qual o homem é, em essência, ambos e, pelo mesmo argumento, hupsipolis e apolis, sendo essa uma parte essencial da definição da estranheza superlativa do homem - nos parece que essa figura não somente captura algo tanto da situação paradoxal do homem contranaturalmente não-político como Aristóteles o descreve (que é, de fato, como vimos, qualificado como apolis) quanto do proeminente e intrinsecamente problemático Homem Ideal que, in extremis, Aristóteles tenta reconectar a polis da qual ele, entretanto, não é parte.

É curioso (talvez até um pouco estranho), então, que Derrida, que lê partes dessa mesma passagem da Introdução à metafísica nos dois anos dos seminários de $A$ besta e o soberano (ele já toca, de fato, nessa questão no recentemente publicado seminário de 1964-65 sobre Heidegger), o primeiro ano se concentrando no deinon como estranho (DERRIDA, 2009: 356; 365), o segundo mais detalhadamente no Gewalt e no Gewalt-tätige (DERRIDA, Jacques, 2009: 391; 285) e seu aparente limite na morte, que são temas centrais nessas páginas da Introdução à metafísica - e que certamente conhecia o curso de Hölderlin de 1942, a que se refere ao menos de passagem em seminários ainda inéditos -, em lugar algum Derrida, até onde sei, chega a citar

\footnotetext{
${ }^{13}$ Heidegger retorna brevemente ao hupsipolis apolis na conferência seguinte, Parmênides (1942), GA 54, traduzido por André Schuwer e Richard Rojcewicz (Bloomington: Indiana University Press, 1992: 90). Essas passagens são objeto de comentário detalhado por Gregory Fried em Heidegger's Polemos: From Being to Politics (New Haven; London: Yale University Press, 2000), que dá a base para a compreensão de Slavoj Žižek desse motivo em, por exemplo, "Why Heidegger Made the Right Step in 1933", International Journal of Žižek Studies, v. 1, n. 4, 2007: 1-43. A referência explícita a Fried desaparece na versão retrabalhada de parte desse material em Žižek's Violence: Six Sideways Reflections (London: Picador, 2008: 68-72. Eu polemizo com as interpretaçôes de Fried e Žižek desse momento de Heidegger em Moments of Madness (no prelo). Embora Fried se refira de passagem à breve discussão no curso Parmênides, é estranho que ele não mencione o tratamento muito mais longo (também de 1942) no curso Hölderlin's Hymn "The Ister". Derrida muito ocasionalmente se refere a esse curso, notadamente em seu seminário de 1989-90 Manger l'autre, mas creio que em lugar algum à discussão do hupsipolis apolis.
} 
essa surpreendente figura do soberano da hupsipolis apolis como lida por Heidegger. Ele esconde, aqui, em plena vista, essa figura que parece intrínseca à compreensão tanto da estranheza do homem quanto da violência que tal estranheza acarreta, essa figura da hupsipolis apolis que poderia muito bem descrever de forma bastante precisa a estranha convergência do soberano como besta e da besta como soberano, a hesitação mesma entre "a besta $e$ o soberano" e "a besta é o soberano" (DERRIDA, Jacques, 2009: 39), a posição indecidível do pambasileus.

O pambasileus é uma besta, e não qualquer besta, mas, como parece, o lobo. Canis lupus pambasileus é o nome latino do lobo Yukon, também conhecido o lobo negro do Alasca, considerado uma das maiores subespécies da canis lupus no mundo, aqui agora se retirando sorrateiramente, à pas de loup.

Tradução de Alcides Cardoso dos Santos

Referências bibliográficas

ARISTOTLE. Aristotle in 23 Volumes. v. 21. Trad. H. Rackham. Cambridge, MA: Harvard University Press; London: William Heinemann Ltd., 1944.

BATAILlE, Georges. Oeuvres complètes, t. VI. Paris: Gallimard, 1973.

Cuvres complètes, t. VIII. Paris: Gallimard, 1976a.

. Euvres complètes, t. VII. Paris: Gallimard, 1976b.

BENNINGTON, Geoffrey. "For better or for worse (There again...)", Discourse, v. 30, n. 1-2, Michigan: Wayne State University Press, 2008:191-207.

DERRIDA, Jacques. The Beast and the Sovereign. v. 2. Trad. Geoffrey Bennington. Chicago: University of Chicago Press, 2011.

. The Beast and the Sovereign. v. 1. Trad. Geoffrey Bennington. Chicago: University of Chicago Press, 2009.

. Rogues: Two Essays on Reason. Trad. Pascale-Anne Brault e Michael Naas. Stanford: Stanford University Press, 2005.

. Voyous. Paris: Galilée, 2003.

. Writing and Difference. Trad. Alan Bass. Chicago: University of Chicago Press, 1978: 251-77; 253.

. "De l'économie restreinte à l'économie générale: un hégélianisme sans réserve”. In: L'Ecriture et la différence. Paris: Seuil, 1967: 369-406.

HEIDEGGER, Martin. Introduction to Metaphysics. Trad. Gregory Fried e Richard Polt. New Haven: Yale University Press, 2000.

KANT, Immanuel. The Metaphysics of Morals. Trad. Mary Gregor. Cambridge: Cambridge University Press, 1996.

NEWMAN, William L. The Politics of Aristotle. v. 1. Oxford: The Clarendon Press, 1887. 
SCHMITT, Carl. Political Theology: Four Chapters on the Concept of Sovereignity. Trad. George Schwab. Chicago: University of Chicago Press, 1985.

STEINER, George. Antigones. New Haven: Yale Univ. Press, 1996.

Geoffrey Bennington nasceu em 1956, nos Estados Unidos. Trabalhou na Universidade de Sussex (Inglaterra) e é atualmente professor de Francês e Literatura Comparada na Universidade de Emory (EUA), membro do Colégio Internacional de Filosofia (Paris) e professor de filosofia na Europen Graduate School (Suíça). Tradutor de diversos livros de Derrida, Bennington é membro da equipe que traduz os seminários de Derrida para o inglês. Publicou, entre outros, Jacques Derrida (Seuil, 1991; em colaboração com Derrida), Dudding: desnoms de Rousseau (Galilée, 1991), Legislations: the Politics of Deconstruction (Verso Book, 1994), Interrupting Derrida (Routledge, 2000), Not Half No End: Militantly Melancholic Essays in Memory of Jacques Derrida (Edinburgh University Press, 2010) e Géographie et autres lectures (Hermann, 2011).

Recebido em: 25/08/2014. Aprovado em: 15/09/2014. 